gravitation, when it comes to light, will be of the saune kind.

In particular, the molecular aspect of reaction in gases is passed under review. Reasons are brought forward for holding that in gases all ultimate reactions are of necessity mono- or bi-molecular. If this be so, the important work now proceeding with regard to the effect of impurities in promoting or inhibiting gaseous reactions must lead to fuller knowledge of the transient molecules or radicals which are formed in the destructive encounter of a pair of the reacting molecules, and are the carriers or intermediaries leading finally to poly-molecular change; while the same transient combinations may be approachable independently from another side as affording. the interpretation of the complex banded spectra of emission or absorption in gaseous media.

The very remarkable and most fruitful and prophetic symbolic theories of molecular structure, especially for the complex molecules of organic chemistry, have not yet proved capable of dynamical interpretation; it seems necessary, however, to admit, on account of the wide range of physical properties that are nearly atomically additive, that stereochemical collocations do represent in some real way the actual aggregation of the atoms instead of mere symbolical representation of it. Recent investigation appears to bring out in certain cases a somewhat definite relation between the configuration of the molecule and the crystalline form of its physical aggregations, which, though reasonable, could not have been foreseen a priori; exact crystallographic measurements may thus in time afford another intimate clue to the molecular structures in related series of compounds.

\section{A NEW METHOD OF STEREOSCOPIC PHOTOGRAPHY.}

A $\mathrm{N}$ entirely novel suggestion for the production of stereoscopic photographs is proposed by Prof. G. Lippmann in the current number of the Comptes rendus of the Paris Academy of Sciences (March 2). Let a lens be constructed of a material possessing a refractive index $n$, the segments forming the front and back of the lens having the same centre of curvature and the ratio of the radius of curvature of the front segment to that at the back being $n-\mathrm{r}$. The front surface is the receiving lens, and corresponds to the lens of the eye; the back surface is covered with the sensitive emulsion, and corresponds to the retina, Owing to the chosen relation between the curvatures of the two faces an image of a point is formed by the front surface on the back one. The system is reversible; a ray of light proceeding from any point of the receiving surface will pass out at the front over exactly the same path as that taken by the incoming light in acting on the sensitive film, and this will be true in spite of any imperfection of the lens surfaces.

Prof. Lippmann now imagines a material such as celluloid moulded back and front, so that the whole surface is covered with microscopic cells, each of which is an elementary cell possessing the properties of the single lens described above. The whole film resembles the compound eye of insects. This plate, sensitised, is exposed in full daylight to the objects to be represented, no photographic lens being required. The result of the operation would be a series of microscopic images fixed each on the "retina" of one of the cells. Seen from the side of the sensitive layer, the whole plate would present a uniformly grey appearance. But seen from the front and illuminated from behind the plate (supposed converted into a positive), the photograph would appear, and would possess the following peculiarities. It would appear in true relief, exactly as in nature, and shifting the eye about would produce a change in the photograph seen, the effect being as if the observer stood in front of a window. By stepping from side to side, in the latter case, fresh portions of the landscape would come into view, the whole always being bounded bv the four sides of the window. In the case of such a piate as that described, the effect would be precisely similar.

As the author remarks in the paper, the technical difficultirs in the prevaration of such a plate would be verv great. The chief difficulty would be the fulfilment of the con- dition necessary for the clear definition of each image in each elementary cell; the ratio, of the radii of curvature must be equal to $n-\mathrm{r}$. Considering the thickness of the film, this difficulty would appear to be insuperable, but it is to be hoped that an attempt will be made to put this idea into practice, however imperfectly.

\section{UNIVERSITY AND EDUCATIONAL INTELLIGENCE.}

CAMBRIDGE.-During the last four years the average income of the botanic garden has been $1708 l$., to which the University chest has contributed 1175l., the rest being made up of money from trust funds and from rents. The botanic garden syndicate now points out that the income is no longer sufficient to cover the expenses. The syndicate estimates that in future, if the gardens are to maintain their high position amongst kindred institutions, some additional income must be found, and it is recommended that the present grant from the University chest to the botanic garden be increased by the sum of $220 l$. per annum.

The next combined examination for sixty-seven entrance scholarships and a large number of exhibitions at Pem. broke, Gonville and Carus, King's, Jesus, Christ's, St. John's, and Emmanuel Colleges will be held on Tuesday, December I, and following days. Mathematics, classics, and natural sciences will be the subjects of examination at all these colleges. Some of the colleges allow candidates who intend to study mechanical sciences to compete for scholarships and exhibitions by taking the papers set in mathematics or natural science. The colleges desire it to be known that any candidate for a scholarship may signify in writing his wish nat to receive the emolument of the same if elected thereto, and that such candidate may be elected to a scholarship which may be honorary only and without emolument, but shall carry with it all other privileges attached to the position of a scholar. The amount thus set free will serve to increase the number of scholarships or exhibitions open to other candidates.

GLASGOW.-Among the honorary degrees to be conferred by the University on April 22 are the following :-LL.D.: Mr. G. T. Beilby, F.R.S., chairman of the governors of Glasgow and West of Scotland Technical College; Colonel David Bruce, C.B.; F.R.S.; Dr. J. J. Dobbie, F.R.S., director of the Royal Scottish Museum, Edinburgh; Mr. R. Kidston, F.R.S.; and Dr.J. C. McVail, county medical officer, Stirlingshire and Dumbartonshire.

Dr. R. Stewart MacDougall, on his appointment to the lectureship in botany in Edinburgh University, has resigned his position as biologist on the staff of the Edinburgh and East of Scotland College of Agriculture.

Mr. A. I. Bowley, reader in statistics in the University of London, will give a course of ten lectures on elementary applications of mathematics to statistical data at the School of Economics, at 7 p.m., on Thursdays, March 26 and April 2, resuming after the Easter vacation on May 7 , and continuing thereafter for seven consecutive Thursdays.

THE Earl of Rosebery will visit University College on the afternoon of Thursday, March 26, and will formally open the new libraries and the new south wing, which includes lecture-rooms for the faculty of arts, the departments of geology, hygiene, and experimental psychology, also large extensions of the departments of applied mathematics, of mechanical, electrical, and municipal engineer ing, and accommodation for the new hydraulic laboratory.

THE first volume of the report of the U.S. Commissioner of Education for the year ending June 30, 1906, has been received from Washington. In addition to chapters summarising the progress made during the year under review in the various departments of American education, the report contains a series of excellent articles on educational administration in various European and other countries. A useful summary of the different sections of the report is provided in the commissioner's introduction, 
and from this digest we notice there were, during $1905-6$, 622 institutions of higher education reporting to the Washington Bureau of Education. The total number of professors and instructors in these institutions reached $23,95^{\circ}$, and the number of students 258,603 - an increase of 9430 on the preceding year. The value of the property possessed by the 622 institutions amounted to 110,8 I $5,400 l$., of which $49,686,100 l$. was the amount of productive funds. The aggregate income of these institutions for the year was $8,956,700 l$. The total value of all gifts reported amounted to $3,543,300 l$.; Harvard University received 443,60ol. ; Yale University, 229, rool. ; Columbia University, New York, 2 ro, oool.; the University of Pennsylvania, ro9,oool.; and the North-Western University, Illinois, and Princetown University, New Jersey, each received about ro5,00ol. In this report, for the first time, the number of students in schools of technology is not given separately, because, as the commissioner points out, there has been an erroneous opinion in Europe and elsewhere that there is no higher technical training in America outside the schools of technology, whereas the ordinary universities grant nearly twice as many degrees in science as the technical colleges, and are doing excellent work in pure and applied science generally.

WE have received a couple of pamphlets (Leipzig : Verlag der Durr'schen Buchhandlung) which indicate the continued interest of the German public in both sides of the question of school reform. One of these pamphlets ("Die Stadt Berlin und das Reformgymnasium ") is a reprint of a strenuous argument, which was originally delivered by Stadtschulrat Dr. Carl Michaelis in 1904, against tampering with the school system of the capital. Dr. Michaelis has brought the statistical portion of his address up to date, and finds in recent educational history nothing to weaken his former contention that the establishment of a Reformgymnasium in Berlin is demanded neither by the success of the reform movement generally nor by the specific educational conditions of the city. Further, while he makes it clear that he is far from opposed to wellconsidered changes in other directions, he defends the old gymnasium against the reformers as an indispensable part of the school system. In particular, he criticises the contention that the lower classes should be preparatory equally to all the recognised forms of secondary school, partly on the ground that the advantage which this arrangement is alleged to give the parent in selecting the school suitable to the abilities of his child is illusory, partly on the ground that no plan devised on these lines can accord with the necessary conception of a gymnasial education. Many of these arguments appear also in the second pamphlet ("Mathematik und Reformgymnasium "), in which Dr. H. Vogt endeavours to show that the teaching of mathematics suffers in respect both of the time given to the subject and of the value of the instruction where it is attempted to superimpose the gymnasial classes upon a foundation common to all the higher schools. The same firm of publishers has reprinted the address delivered in the University of Erlangen by Dr. Richard Falckenberg on the occasion of the centenary of the death of Kant (February 12, 1904).

THE second annual report, dealing with the year 1907 , of the president and treasurer of the Carnegie Foundation for the Advancement of Teaching has reached us. It will be remembered that $\mathrm{Mr}$. Carnegie's gift of two million pounds sterling was intended to serve primarily in the establishment of retiring allowances for teachers in the institutions of higher learning in the United States, Canada, and Newfoundland, but that he left it to be administered for this purpose in such a manner as the trustees might decide to be wise. The fears expressed in some quarters that such a gift in the hands of a limited number of men might prove a centralised power which would hinder rather than aid the progress of eduration do not seem to have been well founded. Since the inauguration of the foundation down to September 30 last, grants hatve been made to 166 persons (eighteen of whom died ditring the period), involving an annual budget of $46.032 l$. of this amount, $20.230 l$. was devnted to retiring allowa!ces in accepted institutions, and $17,702 l$. to retiring al lowances made to individuals. In the group of retire- ments on the basis of age an interesting comparison is made; the number of allowances granted on this basis to professors not in accepted institutions before October, 1906, was eighteen; since then only eight similar allowances have been made. This indicates that the number of aged professors whom on account of their distinguished merit alone the trustees would be likely to add to the holders of allowances is rapidly diminishing. It is also interesting to note that retiring allowances to professors in State universities are made only when the services rendered to learning by the applicant have been of great distinction. As indicative of the number of applications made to the trustees, it may be stated that the files of the foundation show that $5^{\circ 0}$ applications. have been refused. It is satisfactory to learn that when once the principles of award have been decided upon finally, the trustees will see that the retiring allowance comes to the recipient " as a right, not as a charity; as a thing earned in the regular course of service, not a courtesy."

\section{SOCIETIES AND ACADEMIES. LONDON.}

Physical Society, February 14. - Prof. J. Perry, F.R.S., president, in the chair.-Annual general meeting. Address by the newly elected president, Dr. C. Chree. Dr. Chree referred to the magnetic results obtained by the National Antarctic Expedition of 1901-4. The expedition was furnished with magnetographs, and the reduction and discussion of the curves has been done by the National Physical Laboratory. Before describing the results, the president spoke of the nature of the preparations that might be made in any future national scientific expedition. The observers should have a preliminary training lasting over some months, and should be practised in the use of instruments. These instruments ought to be ready for use and fully tested months before the date of the expedition. A programme should be got out in good time, so as to admit of rehearsals by the observers. An inquiry, after the return of the expedition, into the value of the results obtained might be useful in securing that meritorious work in science would not be overlooked. Lantern-slides relating to the diurnal inequalities of the magnetic elements in the Antarctic were exhibited and described. Slides of corresponding Kew results were shown for intercomparison. The president dwelt on the refatively highly disturbed nature of the Antarctic records. In the Antarctic, the declination and horizontal force magnets were practically never at rest. So large and incessant were the disturbances that no idea of the nature of the regular diurnal inequality was obtainable from inspection of individual curves. Diurnal inequalities, however, derived from the curves of single months, and still more of a whole season of the year, proved to be of a comparatively smooth character.

Royal Meteorological Society, February 19.-Dr. H. R. Mill, president, in the chair.-The formation of "snow rollers " observed at Ryton on Dunsmore, near Coventry, on January 29-30, 1907: C. Browett. It seems that the flakes of a light fluffy layer of surface snow are made adhesive by a rise in the temperature of the air above the freezing point, while the under snow remains cold and dry, and the particles of damp surface snow are enabled to adhere to each other, but not to the dry under snow. A strong wind may then push over little proiections of the surface snow and start them rolling, when, of course, they will travel and grow until the resistances overcome the propelling power of the wind. These "snow rollers" vary in size, some being only a few inches in diameter, while at times others have been seen 2 feet or more in length.-Comparison of ships' barometer readings with those deduced from land observations: E. Gold. This paper contained the result of a preliminary investigation undertaken at the Meteorological Office into the relation between the barometer readings taken on ships during their passage across a line between Falmouth and Brest, and the readings deduced for the ships' positions from the observations at these places and the trend of the isobars, on the assumption of regular pressure changes. Taking into account the various causes which can appreciably 